\title{
Service Learning at National Taipei College of Business, 2012-2013: New Perspectives on Community, Peer-Based Education
}

\author{
Siao-cing Guo, David Pendery \\ National Taipei College of Business, Taipei, Taiwan
}

\begin{abstract}
Service learning (also known as peer learning) has received increased attention in tertiary education. By linking learning with authentic volunteer work experience, service learning bridges the gap between theoretical study and practical reality. This practice can increase students' professional knowledge, educational development, self-esteem, and awareness of social responsibility. Service learning became a mandatory requirement for all students at National Taipei College of Business (NTCB; now National Taipei University of Business) in 2011, and this is the focus of this study, extending into the 2012 school year. This course-based program allows undergraduate language majors to put their language skills into practice by teaching peers, and also through other volunteer work. This program has greatly benefitted undergraduate students at the school. This study will examine course data, student reports, and interviews with student teachers. The researchers have documented the implementation of the peer-mentor program at NTCB, and the learning gains experienced among students and the professors who assisted in these processes.
\end{abstract}

Keywords: service learning, peer learning, community learning, collaborative learning, peer teaching, learner-centered approach

\section{Introduction}

According to Cathryn Berger Kaye (2007), "service-learning connects classroom studies with the natural caring and concern young people have for their world. Service-learning allows young people to contribute to solving problems by helping others in their school community, their neighborhood, or around the world” (p. 1). It is exactly these aims of teaching, learning, and community that the authors of this study kept in mind during the implementation of the Service Learning Program at National Taipei College of Business (NTCB) in 2012 and 2013. In this program, students contacted other students from various departments, organized one-on-one tutoring and larger classes, and taught English and other subjects (as noted, students also worked by simply assisting in various departments as well). The authors found through this interaction with their peers and instructors, students acquired substantial knowledge and skills, and this generated personal, academic and even professional growth.

Service learning programs have recently received considerable attention in tertiary education in schools

Siao-cing Guo, associate professor, Ph.D., Department of Applied Foreign Languages, National Taipei College of Business. David Pendery, assistant professor, Ph.D., Department of Applied Foreign Languages, National Taipei College of Business. 
around the world, as well as in elementary and secondary education, with substantial research currently published. Numerous studies have revealed the successes of peer learning, and the authors will examine these works throughout this paper. Benefits include the acquisition of professional knowledge, promotion of self-improvement and self-esteem, improved educational performance, and increased awareness of social responsibility (Eyler, Giles, Stenson, \& Gray, 2001; Guo, 2013). Anderson (1998) notes that embedding service learning into education calls for actively engaged students to construct their own learning growth, and cultivates them to be more involved as citizens in society.

NTCB established a Service Learning Office in 2010, with responsibilities that included the promotion of service learning and the management of related courses and projects at the institution. In 2011, the school mandated that all students at the institution fulfill a Service Learning course requirement before graduation. In order to fulfill that requirement, the Department of Applied Foreign Languages (AFL) designed a peer-tutoring Service Learning Project. This course-based Service Learning Project allowed undergraduate language majors (most of them primarily focused on English) to put their language skills into practice, by teaching undergraduate students in other majors at the institution (many of whom also consider English important in their education). In order to document the implementation of the Service Learning Program, and the learning gains experienced by students, this research will refer to course data, students' own written reports, student interviews, and a final formal report given to classes on the last day of the semester in 2012 and 2013 (in December 2012 the chair of the AFL, Michelle Guo, attended this report given by students, in Professor David Pendery's Advanced Writing Course).

Peer teaching and learning can be of particular use in Taiwan, and the authors hope this paper fills a need within local educational culture. Many Taiwanese college students focus on English language learning, and students are required to take at least one year of English courses. Students receive English instruction with varying course length and teaching methods prior to admission to college, and inevitably they are of varying proficiency levels. In spite of this, they are likely to be grouped in the same class during their English classes in college. To remedy this and better enable students of lower skill levels, universities can encourage higher-performing English majors to conduct peer teaching. Students with higher proficiency can become models for their fellow students, and effect the various advantages the authors will examine in this paper.

Note here that in Taiwan, and also in other countries, educational institutions have only recently considered peer-assisted learning programs, in part because of shortages of funding and highly demanding workloads (Smith, 2008). There is thus a world of possibility waiting to be explored and capitalized on.

According to Eyler and Giles (1999), students involved in service learning developed a better sense of others as well as themselves, and a better appreciation for others' problems and needs. The NTCB Service Learning Program was useful in these ways, enabling students to obtain teaching experience (some of them in fact already had teaching experience), encouraging responsible behavior as they constructed classes and acquired teaching materials, engaging students with one another in scholarly activities and, at the highest level, encouraging a given pride in education, teaching, and learning.

In the following, readers will see that not only did students very much enjoy the NTCB Service Learning Program, they learned essential skills, refined important educational values, and found a new pride and commitment in their school. In this paper, the authors will first examine Research Methodologies (including Participants, Procedures, and Data Collection), and from there present a Literature Review of related research, Program Results (including Class Preparation, Course Management, and Skills Development; Teaching 
Strategies; and Problems Encountered and Suggestions for Improvement), Theoretical Perspectives, and finally a Conclusion.

\section{Research Methodology}

\section{Participants}

This paper's authors will principally examine the students who participated in the Service Learning project in the fall 2012 semester, although the program extended into 2013. Participants include the students registered in two Advanced Writing courses in the AFL (a total of 50), the two teaching assistants in these courses, the two assistant professors, David Pendery and Andrew Rathmann, and the department chair, Michelle Guo, and associate professor. Two teaching assistants, Charlotte Chang and Cindy Chang also participated. Non-English majors in various departments (a total of seven) were the teaching service receivers. The two teaching assistants assumed the role of liaisons, helping all of the participants during the program. The three professors assisted students as needed, and occasionally viewed courses as they were conducted.

\section{Procedures}

The NTCB Service Learning project was carried out in three stages. The first stage was planning, the second implementation, and the final stage reflection, which included the concluding presentation about Service Learning given by students. The design of the project was formulated in the planning stage. The chair, and the two professors held meetings to decide upon the length of time, guidelines, and requirements of the service. The AFL chair designed tutors' sign-up sheets, work logs, and reflection sheets. Planning and preparation took approximately one month. During the implementation stage, instructors guided student teachers in their course design. Student teachers then contacted different departments, arranged students to be taught, and began to host English teaching sessions in the eight-week program. The authors see in these reciprocal processes and relationships a given "constructivist approach to knowledge" in which "knowledge is not simply 'discovered' but is socially constructed. As a result, rather than authority (instructor) transmitting information, students actively construct and assimilate knowledge through a reciprocal process” (Bruffee, 1995; Schon, 1995; Whipple, 1987, in Zhao \& Kuh, 2004, p. 117). In short, Service Learning is a more learner-centered approach to education, and leads to a break away from dependence on teachers and a move toward independence and self-assurance (Brown, 2006). As a result, "learning is deeper, more personally relevant, and becomes a part of who the student is, not just something the student has" (Zhao \& Kuh, 2004, p. 117). The final reflection stage of the project, was comprised, as has been noted, in individual student reports, the final presentation given by students describing their experience, and in this report by the authors.

\section{Data Collection}

The qualitative and/or subjective data in this study were collected from student tutors' work log sheets and reflection reports, as well as interviews with students, reports from the TAs', and meeting notes. A survey of student responses, which will ostensibly provide more quantitative data for research, is in preparation and will be distributed to students in the coming semesters. Readers will note a preponderance of qualitative/subjective data in this report, but the authors maintain that such data is valid, can provide a nuanced view of this program's results, and is in general the most authentic data that can be collected in social science research such as this. Such qualitative/subjective data is scientifically legitimate, and is in fact the primary method in much research examining experience, development, thoughts, and feelings among groups. 


\section{Literature Review}

The following literature review will be necessarily brief, and some items will be reviewed quickly. Naturally, all of the works used as sources in this paper cannot be reviewed, but the authors will endeavor to give an overview, and take a deeper look at a few specific works.

Sánez, L. Fuchs, and D. Fuchs (2005) adopted peer-assisted learning strategies (PALS) with 132 English language students from grade two to grade six in their study. Their results indicate that PALS methods significantly improved reading comprehension, reading fluency, and reading behaviors, compared with the results achieved by a control group. Furthermore, Bicais and Correia (2008) pointed out that young English students in peer learning contexts were more likely to ask for clarification and information about task content, and this aided them in their writing. Their interaction with peers helped them to produce better-written work and to advance their writing skills.

At the college level, Rodríguez-Sabater (2005) investigated the effect of peer teaching on learning Spanish as a foreign language. A very high percentage of the 183 students involved in this study reported improvement in pronunciation, speaking, vocabulary, and grammar, and Rodríguez-Sabater also notes that practice and review were benefits in the peer teaching experience.

In a study of peer partnership in an online learning environment, Cole and Watson (2013) noted the positive impact of peer collaboration in online course discussion and feedback. Online forums allow for "constructive critiquing... and... improved teaching and learning" (p. 117) but, the "role of the online educator is... demanding” (p. 118) and these authors found that in online learning situations, students are more isolated, which creates greater needs for face-to-face interaction and support from peers. Similarly, while online help from peers can be constructive, Higgins (2004) found measurable benefits from face-to-face peer tutoring. Higgins's study examined the course retention rate, of students enrolled in a nursing class, and found that peer tutoring helped to increase not only the academic performance of students but also student retention. The attrition rate in courses decreased from $12 \%$ to $3 \%$ during her program. In a later study by Arco-Tirado, Fernandez-Martin, and Fernandez-Balboa (2011), peer tutoring was also found to be effective in student retention.

In Taiwan, Lee (2010) explored the potential impacts on study achievements among 310 vocational college students involved in peer learning, and found learning motivation, teaching quality, and enhanced learning were realized by participants. Lee further pointed out that peer-assisted learning expanded dimensions of learning in decision-making and socialization skills. The authors of the current paper, as teachers in Taiwan, strongly believe that Service Learning can be advantageous here.

A key work to examine is "Learning Communities and Student Engagement" (2004) by Chun-Mei Zhao and George D. Kuh, which has been referred to (Zhao is a Research Scholar at the Carnegie Foundation for the Advancement of Teaching, and Kuh is Chancellor's Professor at Indiana University, Bloomington). This nation-wide survey in the U.S., covering 80,479 students in 365 four-year colleges and universities, examined a conception of learning communities that extends beyond the ambit of the Service Learning program at NTCB. Zhao and Kuh examined learning communities that extended over various courses in school, which students took simultaneously, and they also included extracurricular activities, joint living arrangements and social networking in their research. These authors also considered more specialized learning communities including underrepresented students and students with disabilities. In spite of these differences, these authors did focus on 
what were essential aims in the NTCB program, including student engagement, personal and educational development, and satisfaction with school. Zhao and Kuh also employed a more standardized instrument in their research, the National Survey of Student Engagement, an annual survey of students in the United States that collects information at hundreds of four-year colleges and universities about student participation in programs and activities. Ultimately, Zhao and Kuh (2004) came to the conclusion that: "Participating in learning communities is uniformly and positive[ly] linked with student academic performance, engagement in educationally fruitful activities... gains associated with college attendance, and overall satisfaction with the college experience” (p. 124).

The authors find that a number of the other studies referred to in this paper are in essence similar to what has been examined thus far. That is, they are generalized studies of Service Learning programs, instructors and students, often employing survey data, program materials, and interviews with students, mostly with similar outcomes, as just indicated above. In this light, a second paper, "Integrating Undergraduate Peer Mentors into Liberal Arts Courses: A Pilot Study” (2008) by Tania Smith (Assistant Professor of Communications Studies at the University of Calgary, Canada) will be examined. In most respects Smith's work is similar to this study, with an initially small group (26 peer mentors in liberal arts studies, but this was extended to seven courses with 473 students), working with student instructors, who conducted classes, led discussion groups, engaged in extracurricular activities, and coached students. Smith employed survey data collected from students, as well as interviews with student mentors. To sum up, Smith states in her conclusion that "these types of programs are proven to have positive educational results," and they are "highly beneficial." These are findings the authors strongly agree with.

With this the authors move on to two extremely well-known authors and works, which will be referred to in theoretical analyses, below.

Howard Gardner's (Harvard University) Frames of Mind: The Theory of Multiple Intelligences (1983/2011), posits that humans have several different modes of intellection, understanding, and information processing. The theory is a critique of standard intelligence theory, such as IQ testing, which is considered too uniform, and worse, often biased. Gardner has identified eight intelligences: linguistic, logic-mathematical, musical, spatial, bodily/kinesthetic, interpersonal, intrapersonal, and naturalistic. Gardner is currently considering two additional intelligences, existential and pedagogical (this last which could apply to Service Learning programs). Gardner's more ranging theory has had its critics, but in general it has been widely accepted among teachers worldwide, who are constructing courses that attempt to address individual student intelligences. Gardner's linguistic, interpersonal, and intrapersonal intelligences, particularly, will be applied to findings below.

Dell Hymes's (1927-2009) Foundations in Sociolinguistics: An Ethnographic Approach (1974) conceives of sociolinguistics as an essential critical perspective on the entire study of language. The scientific problems within linguistics, Hymes contends, combine with social problems, a fact which compels linguists to search for the wider ethnographic foundations of linguistic practices and identity within communities. In this respect, his linguistic studies are always "concerned with social life” and "social phenomenon" (pp. vii, ix)—just as Service Learning. Most important to this study is Hymes's "SPEAKING" paradigm, which includes the following elements: Setting, Participants, Ends, Act Sequences, Keys, Instrumentalities, Norms, and Genres. This theory will be applied to the findings below. 
This shall conclude this literature review. Following is an examination of the results of this Service Learning Program.

\section{Program Results}

Overall, the group of AFL majors (most of whom, as noted, focus on English studies) serving as tutors for their classmates in this program felt that this project brought value to their own learning and development. Students at once improved their own language skills, as well as their teaching skills in this program. They also found that they learned much from their classmates-true community engagement. They were also able to develop skills in class preparation and management. Interestingly, as student teachers examined their own personal strengths and weaknesses, they found that before their teaching experiences, they had not thought about what they were good at and what they still needed to improve upon; however, after having the opportunity to teach others, they became more aware of their own abilities and skills.

Following are some of the lessons these students learned, the skills they advanced, and some of the problems they encountered, with suggestions for improvement.

\section{Class Preparation, Course Management, and Skills Development}

Students described the processes in which they constructed and organized classes at NTCB as mostly enjoyable, including, before the classes began, when they promoted their classes by using posters at school, Facebook, blogs, etc., during course design and as they obtained materials, and finally when they spoke to groups of students as they prepared to launch their classes. Once classes were organized, the teaching students evaluated their students' levels, addressed particular problems, and created course designs accordingly. "In the beginning I tried to find useful materials, I went to the library,” student teacher Candy Liao said. She continued, "I asked the students what they wanted, and what they wanted to learn. I asked students if they wanted to improve their English ability, and they said 'Oh yes.”' In this same vein, another student said in a professional vein, "I tried to figure out their problems, and also found some useful teaching skills. The most important thing is to determine their problems at first, and try to help them improve their skills.” Another student considered the specifics of what was being asked for by students, and considered that, "(1) students think English speaking and listening are difficult; (2) students use the wrong method to memorize vocabulary; (3) students do not know how to find something in common and talk to foreigners." Another bore down into the specifics of English slang and idioms and inquired about "informal usage of English, such as 'I have seen enough of the rat race of city life,' and 'get off the beaten track.'” Some teaching students even extended their advice into other areas, one "providing advice about school teachers, their teaching styles, characteristics, and how they question and score on examinations."

In all of the above, readers can see how students developed skills. They realized that they had to listen and learn to communicate their ideas with others, a vital part of this program. Tutors did not work alone, and they expressed enjoyment working with others. Their teammates helped them gather information and materials. They shared ideas and benefited from people who came up with creative teaching concepts and activities. In addition, they learned about their classmates in different majors, a step into community activity and participation. Because they worked in teams, they could not be focused on their own performance, but had to accommodate others and be patient. As a result, most tutors indicated that they improved their communication skills during this program.

Throughout these processes students were continually required to attain higher levels of language 
knowledge and skill, including vocabulary, reading and writing skills, idiomatic expressions, and grammar. Because they had to explain the materials in English (perhaps occasionally using Chinese), their translation and communication skills also improved.

\section{Teaching Strategies}

According to work logs and post-program interviews, student tutors identified many effective teaching strategies. These included the study of grammar or vocabulary, strengthening speaking skills, preparing for tests (TOEIC, TOEFL, GEPT, etc.), studying Western cultures, or engaging in various classroom activities they enjoyed (watching films and TV; jokes; guessing games and bingo games; and singing and other musical activities); reading, writing and correcting papers; English correspondence; regular tests; and easygoing conversation in class, which elicited responses and promoted feedback from the tutees. In this respect, during these courses, student teachers often opted to create a comfortable and interesting atmosphere, because during lunch recess and after school, their classmates were sometimes tired and tense. "Our team aimed to create a relaxed atmosphere in learning English. Because we think in this way they can learn with enjoyment," wrote Ingrid. With this approach, students and teachers found they enjoyed their own efforts and student participation, with Tina Su, who taught Japanese to her student, reporting, "Everything goes very well. My student is hard-working and full of passion. I'm really glad to teach her." Tina went on that "It's really interesting to have this kind of teaching activity."

\section{Problems Encountered and Suggestions for Improvement}

Because this Service Learning project was a pioneer program at NTCB, some problems were encountered. Students commented on these shortcomings in their written reports, and also during interviews conducted after the program. Prior to the project, the AFL Department had issued a formal announcement to six other departments and promoted the project to department chairs and administration staff. Students from various departments participated in this project voluntarily as tutees. However, because there were many school projects and extracurricular programs held concurrently, it may have been difficult for the departments and their students to keep track of this Service Learning project as it unfolded. The tutors felt that the department should have done even more promotion, so that they could focus on their teaching tasks. This project originally was designed for 10 weeks. The department had to postpone the program two weeks to allow for more promotion time, a small problem in the process. Within the remaining eight-week time frame, one group claimed no student attendance for three weeks, and students failing to show up for class was an occasional problem (Smith also reported this problem, 2008, p. 55).

Tina Su wrote of certain "troublesome” problems in the program. She said that most importantly, initially arranging classes was difficult. Other students echoed Tina's concerns, saying that finding students and setting up the classes was often problematic, and that the department did not do enough to help students in this regard. "We didn't really know where to go.” Tina said. "At the beginning, teachers could not find students. It was slow to start," Candy Liao also said. Tina Su wrote in no uncertain terms, "Please arrange students for this program, and be sure every department knows we [have this program] around the school," while Candy Liao said, "If possible the department could help us to find students beforehand, which means the tutors can save more time getting on track quickly and coping with student's problems efficiently.” This problem even extended into other departments, and Kevin said that "other departments did not know about this program, they were not told. So they asked, 'Do we have the students?’” Professor Guo also observed 
some of these difficulties, and commented that "Scheduling was a problem. The project was difficult to get started, because it involved different departments. When our students approached them, it took a lot longer than expected, and became problematic.” Researcher Tania Smith (2008) encountered problems like these in her work, and wrote that Service Learning required "careful planning and adjustment" during planning and execution (pp. 62, 63, 62).

Students were ultimately found in departments in the school, but this is a key area that needs improvement, and departments must be proactive in aiding students in getting started. And beyond initial scheduling, an organized and clear process is needed-from initial sign-up, to promotion of the program, to final establishment of classes with sufficient numbers of students. Professor Guo plans a more elaborate and well-defined schema in the future, incorporating e-platforms such as the school website and Facebook to promote the project, rather than the traditional methods of paper notices, posters, and flyers. "We needed a platform," she says, "that people cold log into and post their schedules on. If students could log on and see the schedules and see which sessions were open, that would be better."

As referred to by Tania Smith, some students suggested that the department could provide training to students as they prepared to engage in their teaching activities. This seems a very good idea, and would extend the reach of the program into a deeper preparation and instructional facility, which could benefit students for the longer term, providing them with professional skills they could take into the job market when they reach that point. Smith says that "Designing training for peer mentors is essential to a successful peer mentoring program” (p. 52), and her school even has a Collaborative Learning and Peer Mentoring training course. One student said that, "The department should make [the program] more complete before students become involved, and not just throw students into the work."

To continue on this tack, other suggestions students made for improvement included "providing more options to do service that are not only teaching." A few students expressed that they were not genuinely interested in teaching, and thus for them this was not a successful venture. For these students other volunteer activities would be helpful, such as giving campus tours or meeting visitors, translation activities, designing and producing teaching or other school materials, or teaching at other schools, including elementary schools. (Note that in the 2013 Service Learning Program, a number of students did not participate in teaching, and they instead served as assistants in various departments at NTCB. The writers of this paper found that in fact students did not prefer this method, that they would rather teach, and they found their administrative duties much less interesting.)

Other problems teaching students encountered in this program included shyness and hesitance on the part of some students, the above-noted irresponsibility of students not arriving to class, a lack of feedback from students and department personnel, difficulty finding the proper rooms to teach in, certain technical problems such as Internet access, and locating teaching materials.

Serving as tutors to help with English language problems experienced by other students gave the AFL students the opportunity to ask probing questions and conduct further learning. Because of the responsibilities entailed in Service Learning, they became more active in and responsible for their own learning and the learning process of their peers. Moreover, the whole process gave them a sense of achievement and fulfillment. It can be seen that although Service Learning projects like this require a great deal of effort from departments, instructors, and students, the benefits are potentially immense. 


\section{Theoretical Perspectives}

To place these student experiences in a larger framework, the authors first turn to the pioneering work of Dr. Howard Gardner, who posited the conception of "multiple intelligences" in his Frames of Mind: The Theory of Multiple Intelligences (1983/2011). Most readers are probably familiar with Gardner's work, and he has written that, "as a species we human beings are [best] described as having a set of relatively autonomous intelligences” (Multiple intelligences, p. 3). Gardner's eight intelligences were referred to above. Through the lens of multiple intelligences, Gardner has considered "the ways in which societal activities and domains of knowledge emerge and become periodically reconfigured” (Multiple intelligences, p. 10). Analysts are drawn here to consider "societies" of students and their activities, such as seen in this program, and the ways in which their intelligence or "domains of knowledge" are being "reconfigured" through student teaching activities. To refer back to that already discussed, one possibility is that students are seeing new possibilities and an innovative elevation in their own education and learning, by way of programs like Service Learning. Even the name of this program seems to align with Gardner's thoughts (Frames of Mind, 1983/2011), with "service" being a community-oriented social activity (interpersonal and intrapersonal intelligences), and "learning" being a domain of intelligence and erudition, resulting, perhaps, in future-oriented and culturally-constructed "spheres of knowledge" (Multiple intelligences, p. 10).

The authors can link the classroom activities examined in this paper principally to the verbal-linguistic, interpersonal and intrapersonal intelligence patterns. Linguistic intelligence involves sensitivity to spoken and written language. This intelligence involves the ability to effectively use language to express oneself and interact with others, and the capacity to use language in order to achieve goals. These are things the students in this program were consistently called on to do. Students with refined linguistic intelligence are good at reading, vocabulary, writing, telling stories, taking notes, listening, discussing, and debating-all activities that, many students referred to using in their classes. The students in Service Learning were consistently called on to exercise their linguistic intelligence in their communication with others, and in the necessity to teach topics. In terms of practical language usage, Angela stated that students "want to learn more useful words that can help them express themselves," and that her students also desired to improve their writings skills. Melody wrote that "I give them topics to talk about, I also give them some words related to the topics." She continued that, "we try to give them opportunities to speak English as much as possible.” The authors have referred to the teaching students' teamwork, and Ingrid wrote in a linguistic turn that in her team, "I enjoy the times we discuss about that we are going to teach," while Jennifer added that, "I learned a lot from service learning and I also quite enjoyed my team members."

Interpersonal intelligence is concerned with the capacity to understand the intentions, motivations, and desires of other people. It allows one to work effectively with others. Educators need a well-developed interpersonal intelligence, and students in this program were called on to exercise just this. The inter-communication these students engaged in led to good relationships in this way, such that, as noted, easygoing chat and conversation in class were primary methods that students employed. Students found that this interaction and conversation led to affable, mutually-reinforcing collaborative behavior, such that Bob wrote, "We learned from each other, getting to know about each other and becoming friends," and Beth added that, "The activity is good for having the mutual relationship between the tutor and the tutee." Katherine considered the conceptual contours of her teaching approach, and keeping her students in mind wrote that, "I 
have to consider more dimensions in which students may have problems.”

Intrapersonal intelligence entails the capacity to understand oneself, to appreciate one's own feelings, fears, and motivations. Though perhaps a bit broad in its application, students in Service Learning would have been required to interrogate their own motivations and methods as they planned and executed courses, developing an effective "working model" of the self as they sought to interact with other students, and ultimately use that information to regulate their own behavior. Some students considered their own teaching and the impact in had on their own psyche, drilling into the challenges that teaching poses, and the ways that teaching can make teachers reconsider their own intellect and behavior. "I learned to be a good teacher and that I needed patience," wrote Betty, while Jennifer realized that "teaching wasn't as simple as I thought.” Candy wrote that the project had "forced me to understand my weaknesses." In another intrapersonal turn, some students expressed doubt about their own ability to teach the subjects, and how this required them to examine their own aptitude and incentive. "Students asked questions, and sometimes I did not prepare," said Candy Liao. "I could not answer their questions. It was difficult to give them what they needed; it was a big challenge to teach from the beginning." Additionally, as noted, many reflected on how they had learned about themselves in this process, a true intrapersonal examination. "I not only helped them, I helped myself," said Candy Liao, while Nina wrote that, "In this course I found what I am capable of and what I need to improve."

One student even considered questions that branch across the interpersonal and intrapersonal, investigating thinking patterns and intellection that cut to the core of interactive communication and a given self-interrogation, querying that "Sometimes when you think in a Chinese way, it could be more than one answer; however, it's only one answer when you translate it in English. How to think more like English?”

A second theoretical perspective is the Dell Hymes's SPEAKING model. In Dr. Hymes's Foundations in Sociolinguistics: An Ethnographic Approach (1974), he conceived of sociolinguistics as an essential critical perspective on the entire study of language - which may be extending the ambit of the analysis in this paper, but which is nonetheless valuable to keep in mind, as the Service Learning Program is in many respects a deeply interactive, social and as well linguistic exercise. Hymes's SPEAKING model categorizes communicative praxis and human speech acts. His provision of eight elements in his SPEAKING theory did this. The authors will consider the following data with the elements of this model in mind. These elements include: (1) Setting, (2) Participants, (3) Ends, (4) Act Sequences, (5) Keys, (6) Instrumentalities, (7) Norms, and (8) Genres. In terms of the research in this paper, Setting is the college classroom, with students participating as both teachers and students; Participants are these same people, multi-lingual participants of varying skill levels, mostly studying English, but also engaging in other language and academic studies; Ends are the learning and teaching goals of students and teachers - the aims to improve that have been referred to; Act Sequences are in-class behaviors and classroom processes, forms and order, as defined by the teacher and to some extent students - the cooperative interactive behaviors and classroom design that comprise the core of much of the teaching examined in this paper; Keys are the communicative contextualization cues transacting between students and teachers, which establish the tone, manner, or spirit of communicative praxis in class (those small changes in pronunciation, vocabulary, lexis and tenor that can direct the temperament of conversation and interaction); Instrumentalities are the teaching methods and materials used by teachers; Norms are the various cultural and educational standards adhered to in class (politeness, hard work, teamwork, unselfishness, cooperation); and Genres are the various kinds of speech acts or events that take place in class: storytelling, jokes and games, conversation, Q\&A, 
presentations, discussion and debate. All of the above suggests and points to fully transactional communicative practices and exercise, as the students in this program engaged in.

\section{Conclusion}

The authors hope the above analysis has given a thorough picture of the NTCB Service Learning Program. This project has produced a significant increase in students' intellectual, professional, and personal growth, and that students were proud that their activities elevated the quality of education at their school, and led toward a genuine social interactivity and newly configured domains of knowledge and experience (as suggested by Howard Gardner, above).

Professor Guo states that in addition to students having "a sense of achievement in this program," it was also "absolutely a benefit for the school, and I think we should do more." She continued, "I think the value of the program is tremendous. It's not just a win-win situation, it's more. It helps with participating students, and also students who receive the instruction. I believe the student instructors benefitted from the program."

Future programs will be a challenge Guo says, but "there will be other opportunities and projects for students. Everybody involved in this project has learned a thing or two about helping students and the problems students have.” It can be seen from these comments that both teachers and students enjoyed this opportunity, and that they learned from it.

The results of this study show that, in addition to learning from the professors' lectures and teaching approaches, students were able to learn from their peers through observation, interaction, and team teaching. Student tutors were given the opportunity to create a supportive environment for themselves and for other students, and this community learning activity has yielded rich fruit. Through this project, these students developed a sense of achievement and became valuable assets and/or resources for their school, and even their local, community. In future programs, faculty members can find more ways to help students find connections both inside and outside their classrooms. Simultaneously, they can strengthen collaboration with other faculty and staff for additional Service Learning opportunities.

Note here that there were limitations in this study. First, this project was not a long-term project (although it has extended over two semesters now). Student tutors engaged in only eight weeks of actual service work. As well, the collected data was mainly qualitative and/or subjective; there was relatively little quantitative data - but the authors have commented how such qualitative data is valid. In spite of these small shortcomings, the positive outcomes of service learning on student tutors and the student community as witnessed by the researchers were compelling.

To conclude, at a high level students have learned lessons, first, in idealistic public-spirited efforts - Nandan and Scott (2011) say that Service Learning programs "fall along a continuum from charity to social justice” (p. 26). In this light, the authors' hope, again optimistically, is that students have seen a view into volunteer service in their communities, the value of teaching others in need, and personal satisfaction and collective contribution. Additionally, they have honed pragmatic, job-oriented skills, which will strengthen their own resources going forward in advantageous ways. In sum, Service Learning communities are "educationally purposeful activities" yielding "high levels of student learning and personal development” (Zhao \& Kuh, 2004, p. 115), which may be implemented in Taiwan again in the future, bringing illuminating "points of light” (to borrow from George H. W. Bush) into education here. As a final word, and looking ahead, one student, Claire, said optimistically that, "Through this tutoring experience, I can know what I need to work on 
in the future," while Monica wrote simply that, "I'm very glad to have this opportunity to teach other students English.”

It is hoped that the results of this study will contribute to the development of Service Learning programs in Taiwan and abroad.

\section{References}

Anderson, J. (1998). Service learning and teacher education. Washington, DC: Eric Clearing House on Teaching and Teacher Education. Retrieved from http://chiron.valdosta.edu/whuitt/files/service2.html

Arco-Tirado, J. L., Fernandez-Martin, F. D., \& Fernandez-Balboa, J. (2011). The impact of a peer-tutoring program on quality standards in higher education. High Education, 62(6), 773-788.

Berger Kaye, C. (2007). Bringing learning to life: What is service learning?. Retrieved from http://www.lacoe.edu/Portals/0/ Curriculum-Instruction/S-L\%20parent\%20guide\%208x11.pdf

Bicais, J., \& Correia, M. G. (2008). Peer-learning spaces: A staple in English language learners’ tool kit for developing language and literacy. Journal of Research in Childhood Education, 22(4), 363-375.

Brown, H. D. (2006). Principles of language learning and teaching (5th ed.). New York: Pearson Longman.

Bruffee, K. A. (1995). Collaborative learning: Higher education, interdependence, and the authority of knowledge. Baltimore, MD: Johns Hopkins University Press.

Cole, K. S., \& Watson, D. (2013). Academic writing within an online learning environment: Assessing the impact of peer evaluation on lesson planning, execution and assessment. Journal of International Education Research, 9(2), 115-126.

Eyler, J., \& Giles, D. E. (1999). Where's the learning in service learning?. San Francisco: Jossey-Bass Publishers.

Eyler, J., Giles, D. E., Stenson, C. M., \& Gray, C. J. (2001). At a glance: What we know about the effects of service learning on college students, faculty, institutions, and communities, 1993-2000 (3rd ed.). Retrieved from http://compact.org/wp-content /uploads/resources/downloads/aag.pdf

Gardner, H. (1983/2011). Frames of mind: The theory of multiple intelligences (3rd ed.). New York: Basic Books.

Gardner, H. (2011). Multiple intelligences: The first thirty years. Harvard University, Massachusetts, USA. Retrieved from http://howardgardner01.files.wordpress.com/2012/06/intro-frames-of-mind_30-years.pdf

Guo, S. C. (2013). Community teaching practice for greater learning. International Journal of Applied Linguistics and English Literature, 2(1), 208-215.

Higgins, B. (2004). Relationship between retention and peer tutoring for at-risk students. Journal of Nursing Education, 43(7), 319-321.

Hymes, D. (1974). Foundations in sociolinguistics: An ethnographic approach. Philadelphia: University of Pennsylvania Press.

Jackson, C. K., \& Bruegmann, E. (2009). Teaching students and teaching each other: The importance of peer learning for teachers. Retrieved from http://www.nber.org/papers/w15202.pdf?new_window=1

Lee, I. C. (2010). The effects of learning motivation, total quality teaching and peer-assisted learning on study achievement: Empirical analysis from vocational universities or college students in Taiwan. The Journal of Human Resource and Adult Learning, 6(2), 56-73.

Nandan, M., \& Scott, P. (2011). Service learning and community-based partnership: A model for teaching macro practice social work. Journal of College Teaching and Learning, 8(8), 25-37. Retrieved from http://journals.cluteonline.com/index.php/TLC /article/view/5319

Rodríguez-Sabater, S. (2005). Utilizing undergraduate peer teaching assistants in a speaking program in Spanish as a foreign language. Foreign Language Annals, 38(4), 533-543.

Sánez, L. M., Fuchs, L., \& Fuchs, D. (2005). Peer-assisted learning strategies for English language learners with learning disabilities. Exceptional Children, 71(3), 231-247.

Schon, D. A. (1995). The new scholarship requires a new epistemology. Change, 27, 27-34.

Smith, T. (2008). Integrating undergraduate peer mentors into liberal arts courses: A pilot study. Innovative Higher Education, 33(1), 49-63. Retrieved from http://www.units.muohio.edu/saf/reslife/reslife/manuals/edl301/EDL377/Articles/Integrating\% 20Undgraduate\%20Peer\%20Mentors\%20into\%20Liberal\%20Arts\%20Courses.pdf

Wenger, E. (1998). Learning in communities of practice. Cambridge: Cambridge University Press.

Zhao, C. M., \& Kuh, G. D. (2004). Learning communities and student engagement. Research in Higher Education, 45(2), 115-138. Retrieved from http://home.ubalt.edu/ub78145/My\%20Library/storage/HV3TEDZ2/12231609.pdf 